\title{
Regenerative Textiles: A Framework for Future Materials Circularity in the Textile Value Chain
}

\author{
Miriam Ribul
}

check for updates

Citation: Ribul, M. Regenerative Textiles: A Framework for Future Materials Circularity in the Textile Value Chain. Sustainability 2021, 13, 13910. https://doi.org/10.3390/ su132413910

Academic Editors: Valentina Rognoli and Carla Langella

Received: 9 October 2021

Accepted: 10 December 2021

Published: 16 December 2021

Publisher's Note: MDPI stays neutral with regard to jurisdictional claims in published maps and institutional affiliations.

Copyright: (C) 2021 by the author. Licensee MDPI, Basel, Switzerland. This article is an open access article distributed under the terms and conditions of the Creative Commons Attribution (CC BY) license (https:// creativecommons.org/licenses/by/ $4.0 /)$.
Materials Science Research Centre, Royal College of Art, London SW7 2EU, UK; miriam.ribul@rca.ac.uk

\begin{abstract}
Materials science breakthroughs have regenerated high value fibres from end-of-life cellulose-based textiles that can be introduced into existing textile fabrication processes from raw material to textile product in established textile value chains. Scientific developments with regenerated cellulose fibres obtained from waste textiles suggest their potential to replace virgin resources. The current scale-up of regeneration technologies for end-of-life cellulose-based textiles towards pilot and commercial scales can potentially achieve a future materials circularity, but there is a lack of a long-term view of the properties of materials after consecutive recycling stages take place. Cellulose-based materials cannot be infinitely recycled and maintain the same quality, a factor which may provide new challenges for future textile processes in the context of the circular bioeconomy. This paper maps collaborative design and materials science projects that use regenerated cellulose obtained from waste feedstock according to materials in the value chain they seek to substitute. It also presents four new processes that use regenerated cellulose materials in relation to their intervention in the value chain (as determined in a PhD investigation). A framework is presented to demonstrate how these circular material design processes take place at earlier stages of the textile value chain after subsequent regeneration stages.
\end{abstract}

Keywords: textile value chain; textile processes; interdisciplinary collaboration; materials circularity; circular economy; regenerated cellulose

\section{Introduction}

The substitution of environmentally impactful fibres and materials with circular biobased alternatives that demonstrate the same or similar properties is both a scientific and design endeavour. By introducing these bio-based materials into established textile value chains, however, these alternatives do not contribute to changing the current textile production model and its associated environmental and social impacts. Recently, a shift to bio-based materials has been found in the supply of alternative cellulose sources. These international materials science breakthroughs of new improved chemical solvents led to the use of waste cotton textiles as the cellulose source for circular chemical regeneration processes. Regenerated cellulose fibres are manufactured from cellulose, the most abundant organic compound occurring on earth [1]. Current regenerated cellulose production at a commercial scale uses wood pulp as the cellulose source, which is shredded and pretreated so that the cellulose can be dissolved into a liquid using chemical solvents that break down the molecular structures between each polymer chain [2]. The cellulose dissolution is then regenerated into a new molecular structure in a coagulation bath to remove the solvent and is formed, for example, into a fibre, film or foam [3]. Commercially available regenerated cellulose fibres are produced either with harsh chemicals in a viscose process or through a more sustainable lyocell process [4]. The 'so-called cellulose gap' [5] (p. 4030) describes the decrease in cotton production due to rising costs, the use of large amounts of water and pesticides and the need to grow food on agricultural land for a growing global population that is expected to reach 8.5 billion by 2030 [6]. Man-made cellulosic fibres are considered to be a substitute for cotton due to their suitability for the existing textile value 
chain $[4,5,7-10]$. The resulting fibres look and feel similar to silk; however, they behave like cotton in terms of its water absorbency [11,12], making them suitable for textiles and garments. The history and production of regenerated cellulose evidence that these fibres are evaluated against existing materials in the textile value chain.

There is a gap in research and industry projects exploring beyond the transformation of cotton textile waste into regenerated cellulose fibres, such as when these fibres become the feedstock for future lifecycles. Currently, recent scientific developments of regenerating cellulose fibres from end-of-life textiles are reaching a commercial scale. In 2015, the percentage of wood-based cellulosic fibres in the global market sat at approximately $6 \%$ compared to the $25 \%$ of fibres using cotton production $[7,13]$, but a bioeconomy of biologically derived materials is predicted to increase with the production of manufactured cellulosic fibres [7]. Pioneering projects have been able to develop high-quality, regenerated cellulose fibres from cotton textile waste [9,14-17], as well as fibre blends [18], cardboard and paper $[4,5,19]$. These projects are listed in Table 1 . Since the scientific developments of these materials are recent, the current chemical recycling of cotton textiles will only be full-scale commercially by 2030 [8]. Re:newcell in Sweden opened a pilot recycling plant in 2017. The plant can transform 7000 tonnes of textiles waste into biodegradable pulp each year [9] and has launched a commercial product 'Circulose' that is obtained from waste denim in 2019 [20]. Research and funding are invested in projects such as Ioncell in order to upscale their recycling processes to reach a commercial scale by 2025 [14].

Table 1. Table listing publication dates, research labs and waste streams used for cellulose regeneration [21].

\begin{tabular}{ccc}
\hline Date & Research Lab & Waste Stream Used for Cellulose Regeneration \\
\hline 2012 & Re:newcell, Sweden & Cotton textile waste \\
2014 & Ioncell, Finland & Cotton textile, paper and cardboard waste \\
2014 & Evrnu, US & Cotton textile waste \\
2015 & SaXcell, Netherlands & Cotton textile waste \\
2015 & Worn Again, UK & Cotton textile waste separation from polyester \\
2017 & Refibra, Austria & Cotton textile waste mixed with virgin wood pulp \\
\hline
\end{tabular}

Once the production of cellulose regenerated from waste textiles reaches a commercial scale, the fabrication of cellulose-based textiles mostly takes place in separated stages in the textile value chain between raw material, fibre, yarn and textile production [12,22], as it is currently demonstrated at a lab and pilot scale (see Sections 2 and 3.1). The replacement of cotton with regenerated cellulose in the established textile value chain relies on a supply of high-quality, strong fibres that can be transformed into yarns for knitting and weaving. There is a problem with pursuing this established textile value chain with regenerated cellulose materials obtained from waste textiles. The chemical recycling of cellulose waste explores cotton and paper waste as its cellulose source to provide strong fibres for existing textile fabrication processes $[4,19,23,24]$. Regenerated fibre, however, has lower strength than cotton fibre [8] and its quality further decreases at each recycling stage [25]. With chemical recycling processes of cotton-based textiles reaching a commercial scale, large quantities of recycled regenerated textiles would generate cellulose materials that would not produce strong enough fibres for woven or knitted textiles [8]. Such 'low value' [25] (p. 122) regenerated materials, therefore, require new interventions in the value chain to make use of these waste resources.

Since the development of cellulose regeneration processes using waste feedstock is recent, textile design and materials science collaborations using this material are a new field of practice too. Most examples of textile design and materials science collaborations with regenerated cellulose obtained from waste textiles are taking place at Aalto University in Finland [1,3]. Aalto established collaborative cellulose regeneration investigations between the textile design and the organic chemistry departments in 2012 [26]. These are on-going in the annual ChemArts programme, as well as having taken place in the Design-Driven 
Value Chains in the World of Cellulose (DWoC) project from 2013-2018 [23]. The DWoC project demonstrates the versatility of cellulose in product applications, new technologies or established processes. The outcomes of textile design and materials science collaborations in this field act as prototypes that communicate the potential of utilising regenerated cellulose in the established textile value chain. This is evident in the projects carried out by Aalto University's Ioncell research group, which makes 'demo products' to provide a convincing argument for the use of the technology [27]. This approach can also be seen in the 'demonstration economy' envisioned by Innventia Global Outlook, where ideas and new concepts for a 'cellulose-based society' thrive only when based on 'persuasive demonstration' [28] (p. 63).

Concurrently, cellulose sources for regenerated cellulose textiles are originally derived from bio-based wastes; therefore, the resulting textiles would ideally be compatible with the biological cycle, in the context of the circular economy. However, there are many variables that can disrupt the chemical recycling process of cellulose-based textiles. Each stage of the textile lifecycle can add barriers to the possibility of recycling in the materials science laboratory. These include: the addition of dyes, finishes, fixings and embellishments [29]; the degradation of the material through wash and wear in the use phase [30] and the collection and sorting of the materials [31]. While de-dyeing can be circumvented through new solvent technologies [1], the lack of chemical transparency, for example, in the finishing stage [32], is a barrier to reintroducing materials into the recycling process. A compatibility between textile fabrication and finishing stages can be achieved with mono-material textiles, in which cellulose is not mixed with petroleum-based resources that disrupt the chemical recycling technologies developed for cellulose-based materials [33]. Other barriers to the recycling process can arise in textile production. This could be caused by the way in which the textile value chain and the supply chain stages between the recycling of the cellulose and manufacture often occur in separate global locations. Current chemical recycling breakthroughs of cellulose waste are being achieved in Europe and North America. Yet, Östlund et al. [8] predict that in a commercial production of cellulose, even if the material from recycled sources is produced in Europe, the production of fibres would then be exported into a global supply chain for textile production. In this scenario, toxic chemicals can be added at each stage in the fabric's production [32], making compatibility in the fabrication and finishing processes of textiles difficult to obtain. Together with the prospect of the changing properties of cellulose in chemical recycling, new fabrication processes will be needed. These are needed to integrate several stages of the textile value chain in order to create textiles that are appropriate for the context of a circular bioeconomy. The recent developments of scientific research with regenerated cellulose obtained from waste sources offers the opportunity for textile design to intervene at the chemical recycling stage before the material processes are up-scaled into fully commercial textile production that aims for the replacement of materials in current value chains.

This paper presents a framework for 'regenerative textiles' in a future materials circularity in which textile processes respond to the changing properties of regenerated cellulose materials after consecutive recycling stages in the context of the circular bioeconomy. Section 2 describes the method by which textile design and materials science collaborations working with regenerated cellulose obtained from waste textiles are mapped. This is carried out according to the materials they seek to replace in the textile value chain and according to the way in which the practice of the author was developed that resulted in the establishing of four textile techniques, all of which inform this framework. Section 3 evaluates design interventions with regenerated cellulose materials according to the established textile value chain. Section 3.1 maps textile design and materials science collaborations with regenerated cellulose obtained from waste sources and identifies how interventions at the raw material and fibres stages are not explored. Section 3.2 evaluates the four textile techniques developed by the author according to consecutive recycling stages from within the context of the circular bioeconomy. Section 4 concludes with how this framework creates 
opportunities for regenerative textiles, which moves towards fully integrated fabrication and finishing processes in future materials circularity.

\section{Method}

Textile design and materials science collaborative projects exploring regenerated cellulose materials obtained from waste textiles were identified using a literature and practice review. The textile value chain adopted in these projects was used to map the resulting textile applications, as well as the practice work of the author. Finally, the development of earlier interventions in the value chain through the practice work informed a framework for processes in consecutive recycling stages in future materials circularity.

The literature and practice review followed two stages: (i) a review of 'circular economy' reports, academic publications and online project repositories or websites for 'regenerated cellulose', 'design', 'collaborations', 'recycling' and 'textiles', which established the technologies for regenerated cellulose featured in Table 1, as well as the 2012-2021 time frame of the review corresponding to the first developments of these technologies; (ii) a review of interdisciplinary textile design and materials science projects using technologies that enable regenerated cellulose production from waste textiles, in which the practice review of design projects was conducted through project websites, exhibition catalogues, project reports, student theses and the press. Most of the collaborations identified in the review took place at Aalto University; hence, this paper maps projects onto the stages of Aalto's textile value chain model (see Section 3.1).

Figure 1 shows the established textile value chain with an example of fibres produced with the Ioncell-F dry-jet wet spinning technique developed at Aalto [34]: materials science dissolves the post-consumer cotton waste (the cellulose source) and regenerates it into fibres; the fibres are spun into yarns, which is an engineering task [12]; textile designers weave or knit the yarns into textiles; fashion textile designers make a garment or accessory either through sewing the woven textile, or through knitting; dyes and finishes are applied at the stages of fibre, yarn or full textile product. In this value chain, the disciplines of materials science and textile design are each involved in a specific stage in the fabrication of textiles between the raw material and the finished textile product and the fibre is transformed into a textile using the established processes of weaving or knitting. In fact, $57 \%$ of global textiles in 2016 were knitted and 32\% were woven, while nonwovens for textiles only consist of a small percentage [35].

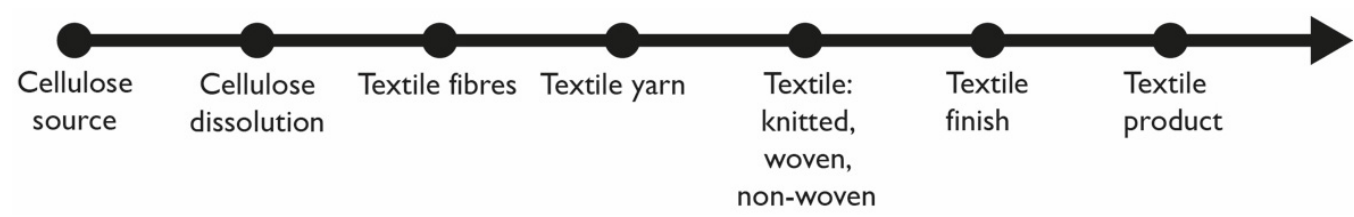

Figure 1. Illustration showing the stages of textile fabrication from raw material to textile product in the existing regenerated cellulose textile value chain.

The four techniques with regenerated cellulose obtained from waste textiles are the result of the author's development of practice through practice-based research in materials science laboratories in Europe where recycling processes using waste cellulose-based textiles take place. The practice work followed the stages of material tests, material experiments and material design processes using the Material-Driven Textile Design methodology developed by the author and described in detail in Ribul et al. [36]. The development of the techniques succeeded in parallel through the following three distinct methodological action stages: an exploration stage of the scientific method for cellulose dissolution to identify and test opportunities for design interventions 'with' the material; a translation stage of the scientific method through the introduction of established design tools and techniques in order to develop transdisciplinary material experiments; and, finally, an activation stage of new circular material design processes through design prototyping. Each of the practice 
stages aimed to develop new fabrication and finishing processes at the raw material stage of regenerated cellulose production by using a cellulose dissolution. The design practice of the author was developed through the introduction of design techniques such as moulding, $3 \mathrm{D}$ printing, bonding and coating at the early stages of the textile value chain. At the same time, a scientific method for cellulose dissolution and regeneration was integrated and led to textile outcomes that are compatible with chemical recycling. Concurrently, the haptic and visual properties of the material and textile samples throughout each practice stage were qualitatively evaluated using tacit textile knowledge informed by the disciplinary background of the author. The qualitative evaluation informed prototyping throughout the practice work where textile properties such as texture, form, strength, lightness, drape, colour, composition and thickness were sought [36].

The resulting processes informed the development of the framework. The mapping of the textile techniques through diagrams and visualisation demonstrates that new value chains were enabled through earlier interventions in the textile value chain, leading to a reduction of processing stages in textile production. Section 3.2 describes how each technique presents opportunities for new processes that respond to the changing material properties in consecutive recycling and regeneration stages. Together, these present a framework for future materials circularity of regenerative textiles.

\section{Results and Discussion}

This section describes where, with the cooperation of materials scientists, textile design projects exploring regenerated cellulose from waste textiles take place in the textile value chain from the cellulose source to the finished textile product. Section 3.1 describes projects that introduce regenerated cellulose into existing textile fabrication and finishing techniques. Section 3.2 maps the fabrication and finishing techniques resulting from the author's research in relation to their intervention in the textile value chain [21]. It demonstrates the framework for early interventions in the value chain in consecutive regeneration stages.

\subsection{Textile Design and Regenerated Cellulose Projects}

\subsubsection{Textile Finishing Stage}

'Finishing' is defined here as chemical and mechanical modifications in woven, knitted or nonwoven textiles including printing, dyeing, thermosetting, pleating or chemical crosslinking processes. In this section, finishing describes printing fabrics. Textile design and materials science collaborations in the $\mathrm{DWoC}$ programme at Aalto University saw, with the help of a 3D-printer, the printing of cellulose onto fabric for textile finishing $[3,23]$. These projects demonstrated that the regenerated cellulose can replace synthetic materials in this process. 3D printers require thermosetting material properties and, therefore, the cellulose sources were adapted to the print process by the materials scientists: the projects used cellulose derivatives such as cellulose acetate, hydrogels, nanocellulose, cellulose-based plastics and pulp fibre composite [3]. Figure 2 maps how 3D printing on fabric takes place at the finishing stage in the textile value chain.

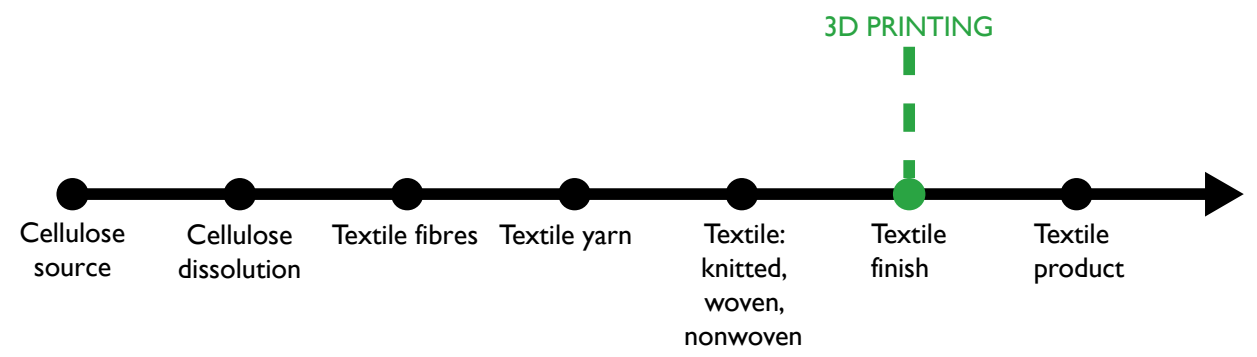

Figure 2. Regenerated cellulose projects with 3D printing at the textile finishing stage [21]. 
Textile designer Tanttu [37] 3D-printed structures on fabric to achieve functional and aesthetic properties on its surface. The project used a direct-write type printer with a nozzle that required plasticised cellulose to enable printing by means of a syringe [3]. 3D printing was mapped as an alternative process against other possible applications at a product and service level: the final products included print applications for sports, work clothes, haute-couture fashion, support clothing and decorative patterns. The service potential included tracking movement with sensors, 3D body scanning, measuring blood pressure, personal wear and professional athletics training [37]. Shrinkage was an undesired effect in the direct-write surface print pattern, as it changes the form of the fabric and the desired print plan cannot be achieved. Cotton fibres were added for a soft surface finish [3] and the dyed cellulose-based 3D printed outcomes were freestanding or set on fabric for functional applications in sportswear and medical science [3]. Based on Tanttu's work, collaborators at Aalto and the VTT Technical Research Centre of Finland Ltd. 3D-printed cellulose derivatives such as cellulose acetate and nanocellulose onto fabric to create functional structures [38]. Cellulose was printed in multiple forms including 'hydrogels, cellulosebased plastics and pulp fibre composites' [3] (p. 51). A cellulose dissolution suspended in hydrogel structures was also printed and then regenerated [3]. In this project, shrinkage for surface modification was a desired effect and 'hard, soft or shrinking structures' could be achieved through the 3D print [38]. In these examples, the 3D printed surface finishes were linked to a specific functionality of the print in a textile application: these included thermochromic inks or other functional powders mixed with the cellulose for flocking effects, or for the replacement of smock stitching and pocket seams.

\subsubsection{Textile and Yarn Stages}

Most projects resulting from textile design and materials science collaborations using cellulose that is regenerated from waste sources focus on demonstrating the viability of the fibres in existing textile fabrication processes. This is evidenced, for example, through the DWoC programme that showcases the materials science possibilities for upcycling waste from cardboard, newsprint and garments into new fibres for textiles [23]. The fibres produced are twisted into yarns with specialist equipment [3]. Figure 3 maps how the following examples take place at the textile processing stages where yarns are woven or knitted into textiles or textile products. The resulting garments and accessories are finished through dyeing.

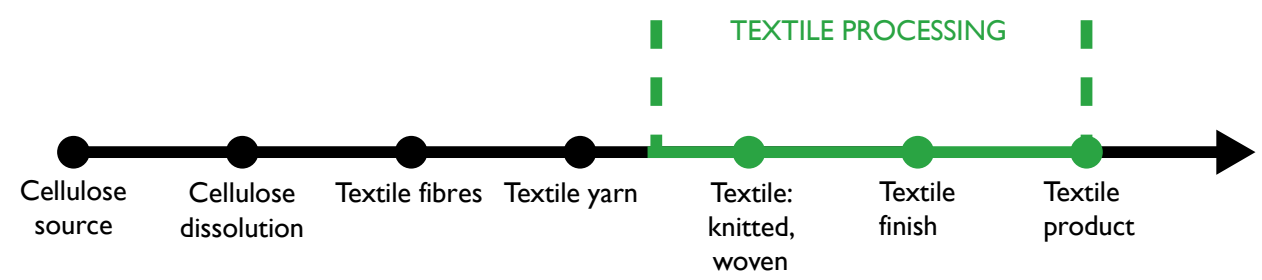

Figure 3. Regenerated cellulose projects with yarns at the textile processing stages [21].

At Aalto University, the Ioncell-F scarf was the first prototype developed with their Ioncell technology by knit designer Marjaana Tanttu in 2013. This was followed by a collaboration with Marimekko for a knitted dress designed by Tuula Pöyhönen and a woven bowtie in 2014 [34]. In 2015, Tanttu knitted samples made from the regenerated cellulose of waste cardboard. In 2017, Pirjo Kääriäinen and Essi Karell developed a knitted jumper to demonstrate the progress made as a result of winning the Global Change Award [39]. At the end of 2017, Tanttu knitted laptop sleeves from regenerated newsprint, evidencing the potential of the technology to create strong fibres from unrefined wood pulp waste containing impurities such as ink [40].

The Swedish company Re:newcell collaborated with KTH, Svenskt Konstsilke AB, Textilhögskolan Borås and Wargön Innovation to produce the first fully recycled dress from waste cotton in 2014 [9] The company cites only waste cotton as the cellulose source to 
make the new fibres [9] and the final artefact demonstrates the potential to replace cotton fibres in established textile processes.

The Dutch Saxcell project at Saxion University developed their first garment made of regenerated cellulose in 2015: a blue jumpsuit [41]. The research was part of the 'From Workwear to Workwear' project (2017-2019). The design of the prototype jumpsuit demonstrates functional and aesthetic qualities to replace cotton fibres in woven textiles for existing workwear products.

US-based company Evrnu developed a chemical recycling process for cellulose-based textiles [42]. In 2016, they produced a pair of woven denim jeans using five old T-shirts that were regenerated into the weft yarn, while virgin cotton was used for the warp in collaboration with denim brand Levi's. In these ways, the project was able to demonstrate the potential to create a denim jean with chemically recycled cellulose fibres from waste cotton feedstock.

\subsubsection{Textile Fibre Stage}

There is no evidence for textile processes in practice-based textile design and materials science collaborations using regenerated cellulose obtained from waste feedstock that begin at the fibre stage. Fibres can only be regenerated from a cellulose dissolution if they meet a specific degree of polymerisation for the chemical recycling process to work [4] (p. 859). The degree of polymerisation describes and measures the length of the polymer chains at the molecular scale of cellulose [4,30,43]. Virgin cotton feedstock, for example, has longer polymer chains than regenerated cellulose fibres [43]. Longer cellulose chains in the dissolved cellulose can produce better quality fibres, while wash and wear can degrade the fibre and reduce its degree of polymerisation [30]. The cellulose dissolution can be extruded in the spinning machine either using a wet, dry or solvent-spinning process and the polymer chains align into new soft, thin fibres [4,22].

Fibres also feature in the DWoC project in the development of technical processes for nonwoven fabrication in materials science [23]. Nonwoven textiles can be produced with varying physical properties. For example, materials scientists developed a foam-forming process for nonwovens from yarns and fibres with various thicknesses [44]. Designer Kinnunen then applied the finished nonwoven to the construction of a shoe. Therefore, textile design in this case did not proceed experimentally with the regenerated cellulose material in its fibre form but instead intervened at the product stage of the textile value chain.

\subsubsection{Raw Material Stage}

The earliest point of the textile value chain is the 'raw' material stage. In renewable resources, this ' $\mathrm{raw}^{\prime}$ ' stage can be pinpointed as unprocessed material such as the cotton plant. Within the context of a circular bioeconomy, the point of 'rawness' of cellulose-based materials could be allotted to various stages, such as at the end-of-life of a collected waste cotton garment or the dissolved and regenerated cellulose fibre at the beginning of the material lifecycle. In fact, within scientific research for producing regenerated cellulose materials from waste cellulose-based textiles, the raw material stage can be considered as being the discarded textile; the milled, post-consumer cotton after unsuitable parts of the garments such as prints or fastenings are removed; the pre-treatment of the material; the dissolution of the cotton with the solvent; or the regenerated fibre [45]. Each raw material stage requires the appropriate process in order to transform the waste textile so that it can begin a new lifecycle. All stages are connected by the fact that cellulose is the building block that is transformed into a liquid or into different solid forms. If textile fabrication processes are to respond to the properties of regenerated cellulose in chemical recycling before fibres are produced, the 'raw' material stage is the liquid state of the material. This liquid state consists of post-consumer cellulose-based textiles and the solvent. Together they form the cellulose dissolution that can be regenerated into a new form through a coagulation bath. From this point on, the paper will refer to this cellulose dissolution when describing the 'raw' material stage for the textile processes developed by the author. 
At the raw material stage, 3D printing is a technology that can use the thermoplastic properties of liquid and solid materials to cure them into a programmed shape [23]. In a project by Salminen and Seppälä at Aalto University, 3D-printed cellulose was tested as a material to replace oil-based polymers in 3D printing via a NScrypt printer [3]. The most common 3D printing technology is Fused Deposition Modeling (FDM), which relies on plastics such as ABS and PLA for its thermoplastic properties [3]. The project developed a 3D printer for cellulose printing (Kataja and Kääriäinen, 2018). To achieve 3D printing, cellulose derivatives provided adhesion between layers that pure cellulose could not provide [3]. The cellulose-based material is formed into a programmed shape based on a digital file through a nozzle that forms the thermoplastic material [23]. The outcome considers its possible applications in biocompatible prosthetics and how this could expand to architectural and packaging applications once the print process is optimised: currently, the shrinking of the cellulose alters the form of the final 3D print and needs to be controlled [46]. The same strong shrinkage after drying was found in Gatenholm's research with 3D printed nanocellulose in Sweden [47]. However, design here only intervenes at the product stage of the textile value chain to create freestanding 3D-printed product applications, meaning that experimentation of textile processes at the raw material stage has not been explored.

\subsection{A Framework for Future Materials Circularity in the Textile Value Chain of Regenerative Textiles}

This section maps the four textile techniques, mentioned above, that evolved in parallel to one another as a result of the author's Material-Driven Textile Design methodology [36]. Each technique demonstrates a design intervention at a different stage of the textile value chain in the fabrication and finishing of textiles.

On the left side of Figure 4, diagrams show how each technique corresponds to design interventions at different stages of the textile value chain. In addition, the new fabrication processes are shown. These processes were enabled by circumventing the established processing stages; they began with the two finishing techniques shown in the first diagram. The reduced steps in the fabrication of textiles between fibre, yarn, textile and finish are visualised in the corresponding circles on the right side of Figure 4. Each circle maps the new textile processes according to consecutive regeneration stages of cellulose-based textiles within circular recycling (see annotations in Figure 4). The diagrams envision how each process responds to the changing material properties of regenerated cellulose at each chemical recycling stage in the context of a circular bioeconomy; they do so by proposing earlier interventions in the textile value chain. When materials are collected for regeneration after each cycle, the quality of the material decreases and the levels of complexity in the fabrication processes are reduced. As a result, the techniques create new value chains for regenerated textiles that begin with the raw material stage of the cellulose dissolution. The evaluation of each technique in this section sees discussion of the corresponding circles. 


\section{TEXTILE TECHNIQUE DESIGN INTERVENTION}

\section{Ist CELLULOSE REGENERATION STAGE:}

\section{TEXTILE FINISHING}

Circular recycling of post-consumer cotton textiles produces fibres and yarns for constructed regenerated cellulose textiles that are finished with regenerated cellulose.

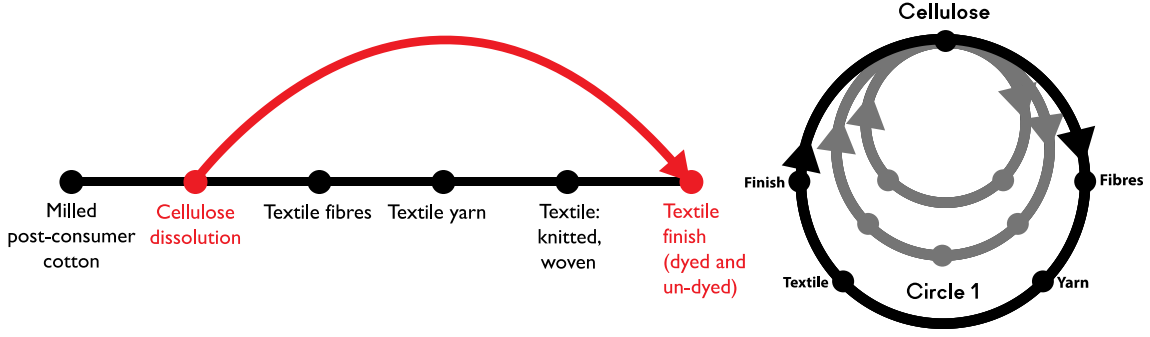

2nd CELLULOSE REGENERATION STAGE:

NONWOVEN TEXTILE FABRICATION

Circular recycling of regenerated cellulose textiles produces short fibres that are fabricated into a nonwoven textile with a regenerated cellulose finish.
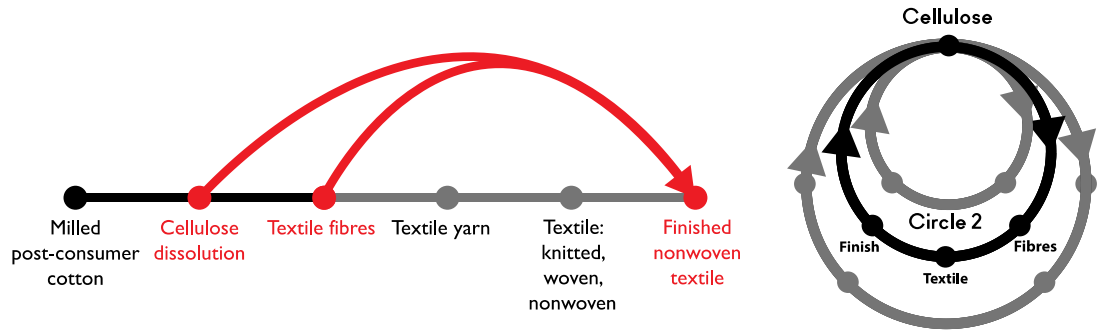

\section{3rd CELLULOSE REGENERATION STAGE:}

COMPOSITE TEXTILE FABRICATION

Circular recycling of regenerated cellulose nonwoven textiles produces a finish that is formed into a textile composite with mechanically milled post-consumer cotton.
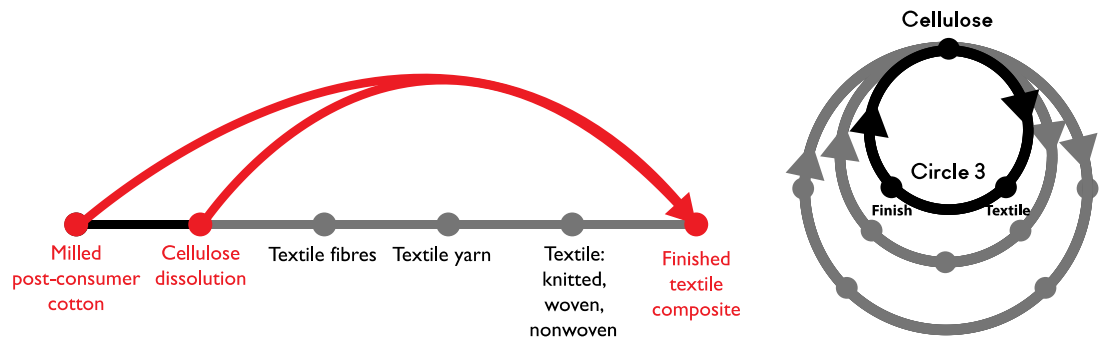

Figure 4. A framework for future materials circularity showing where the textile design techniques intervene in the textile value chain with the corresponding cellulose regeneration stages in a circular recycling model with reduced complexity in fabrication processes between raw material and finished textile [21].

\subsubsection{At the Finishing Stage}

These two processes developed through the author's intervention at the raw state of a cellulose dissolution are situated at the finishing stage in the textile value chain. The textile finishing techniques represent two processes for dyed (Figure 5a) and un-dyed (Figure 5b) circular finishing of a woven or knitted fabric produced from fibres and yarns. These techniques can make use of a low value cellulose dissolution that is not suitable for the fibre regeneration process. 


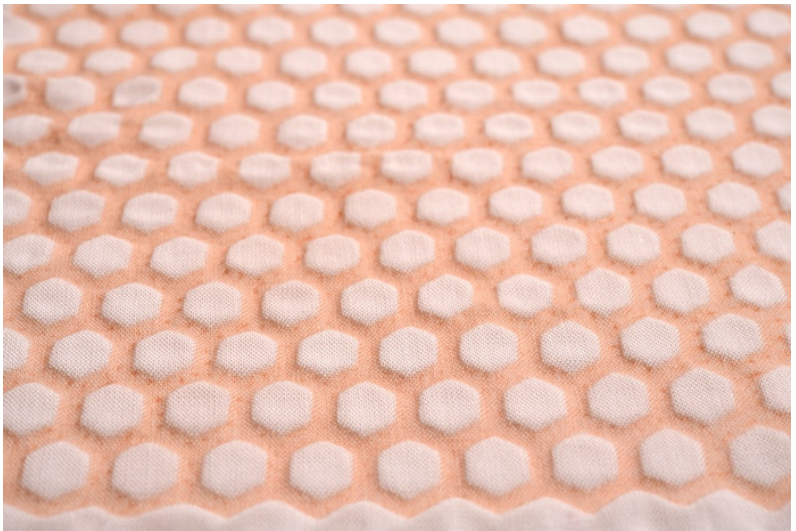

(a)

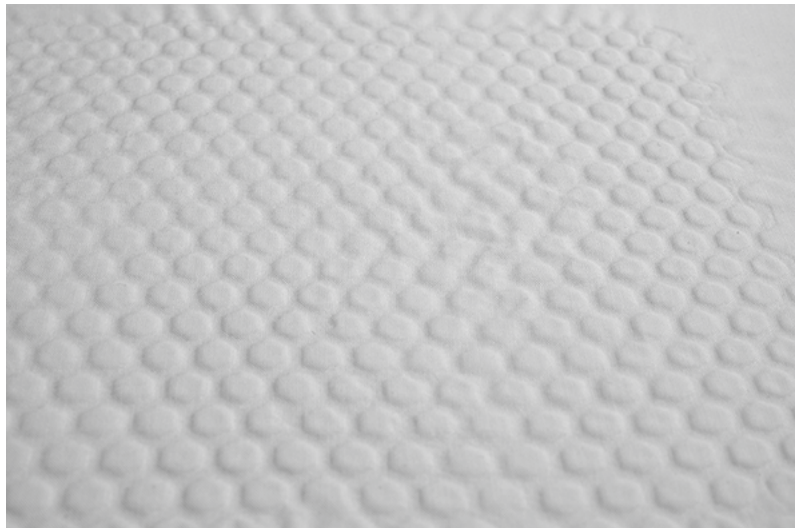

(b)

Figure 5. (a) Mono-material dyed finishing with regenerated cellulose on cellulose-based fabric; (b) Mono-material un-dyed finishing with regenerated cellulose on cellulose-based fabric.

Figure 6 shows how these processes result in linking the raw material stage (cellulose dissolution) with the finishing stage of the textile value chain. By finishing cellulose-based fabrics with a cellulose-based (dyed or undyed) cellulose dissolution, the finished fabric is mono-material and suitable for closed-loop chemical recycling within the context of the circular bioeconomy. Figure 6 shows that these techniques achieve a replacement of materials in the finishing stage in the textile value chain similar to the 3D-printing projects in the DWoC programme discussed in Section 3.1.1.

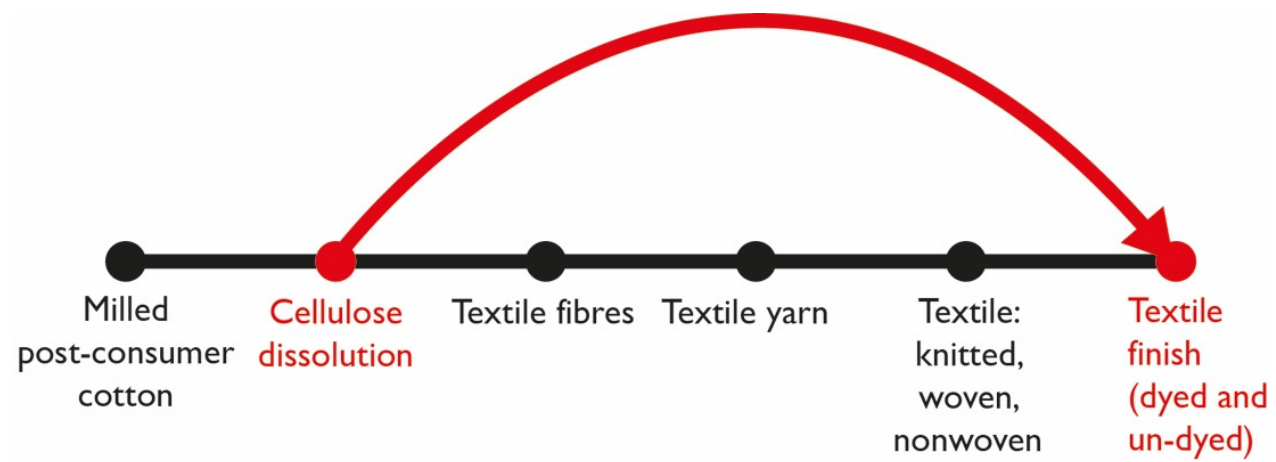

Figure 6. Diagram showing the techniques introducing a dyed or undyed cellulose dissolution in textile finishing [21].

These techniques change the textile finishing process with the cellulose dissolution through a modified textile printing technique developed to deposit it onto fabric [48]. The printing technique changes the visual and haptic properties of the textile through fabric manipulation, finish and shape similar to established textile finishing processes and resulting in outcomes with similar properties [48]. However, in this process, the monomaterial outcome is produced using solely waste textiles and can be regenerated for a new lifecycle. An important consideration of this technique is that the cellulose dissolution is not limited by the degree of polymerisation required for the fibre regeneration process described in Section 3.1.3 and, therefore, can make use of low value chemically recycled materials. Figure 7 shows how the finishing techniques form Circle 1 with the equivalent stages of the established textile fabrication process. In these techniques, the cellulosebased textile finish facilitates the material's circularity as mono-material textile. These techniques, however, rely on woven or knitted cellulose-based textiles as a substrate, which require high value regenerated cellulose fibres and yarns to be produced. When the cellulose-based finish is made from recycled post-consumer content, the cellulose-based substrate may be produced from virgin fibres in a commercial context. Therefore, earlier 
opportunities for a design intervention in the textile value chain were sought, as outlined in the next sections.

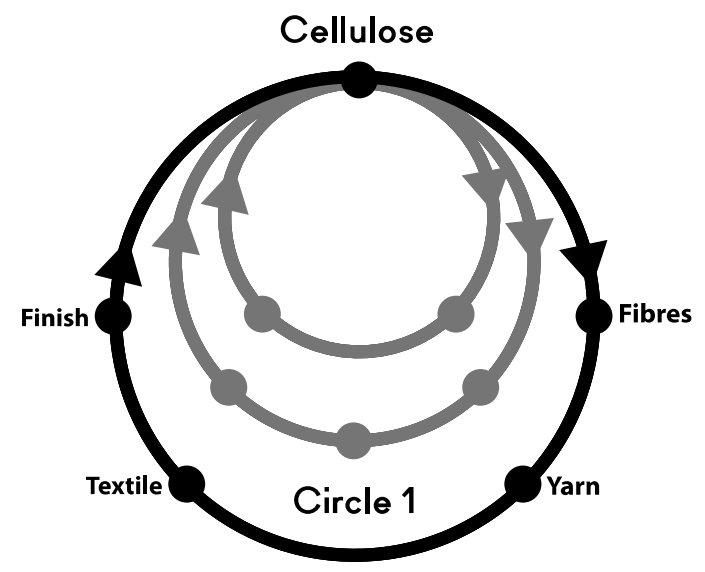

Figure 7. Finishing technique in Circle 1 is the first cellulose regeneration stage after circular recycling of post-consumer cotton textiles [21].

\subsubsection{At the Fibre Stage}

Nonwoven textile fabrication is the third technique developed in the practice-based work of the author (Figure 8). Figure 9 shows that this technique presents a new textile design intervention at the fibre stage in the textile value chain. This technique uses a cellulose dissolution that can be regenerated and spun into fibres using spinning equipment at lab, pilot or commercial scales. Therefore, the design intervention at the fibre stage in the textile value chain has the potential to solely use materials that can be produced from waste sources in the chemical recycling process. Figure 9 shows how this technique combines the cellulose dissolution and the regenerated cellulose fibres to fabricate a finished nonwoven textile. The fabrication technique bonds a web of cellulose-based fibres using the cellulose dissolution and, therefore, a finished nonwoven mono-material is fabricated that is evaluated against fabrication of engineered nonwoven textiles [48]. Iterative prototyping with different regeneration and drying methods has established a nonwoven fabrication process resulting in a soft textile hand feel [21].

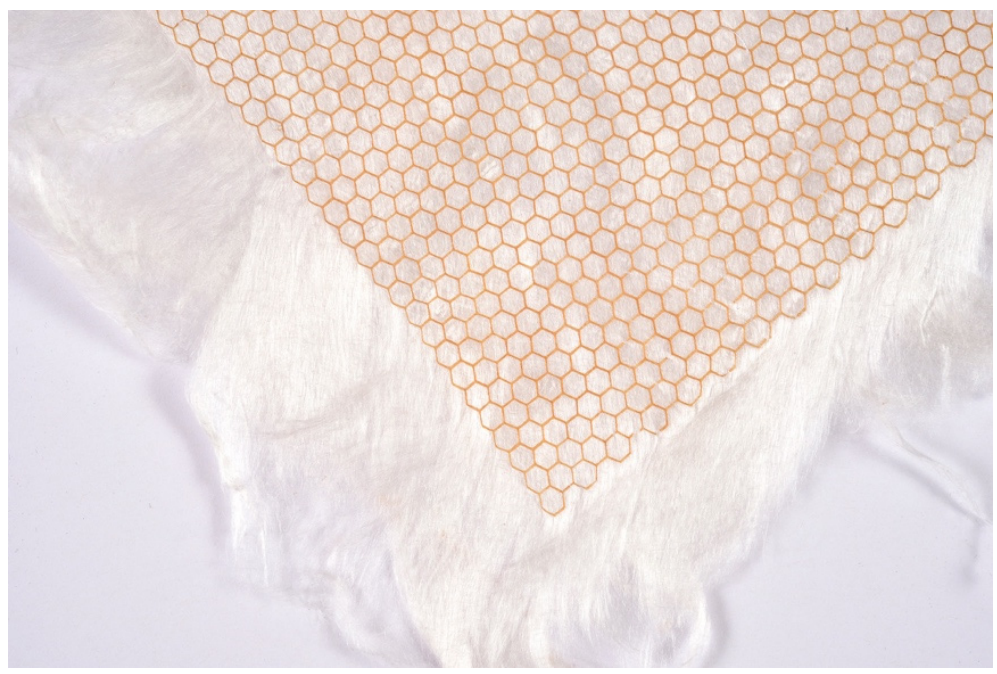

Figure 8. Nonwoven textile fabrication at the fibre stage. 


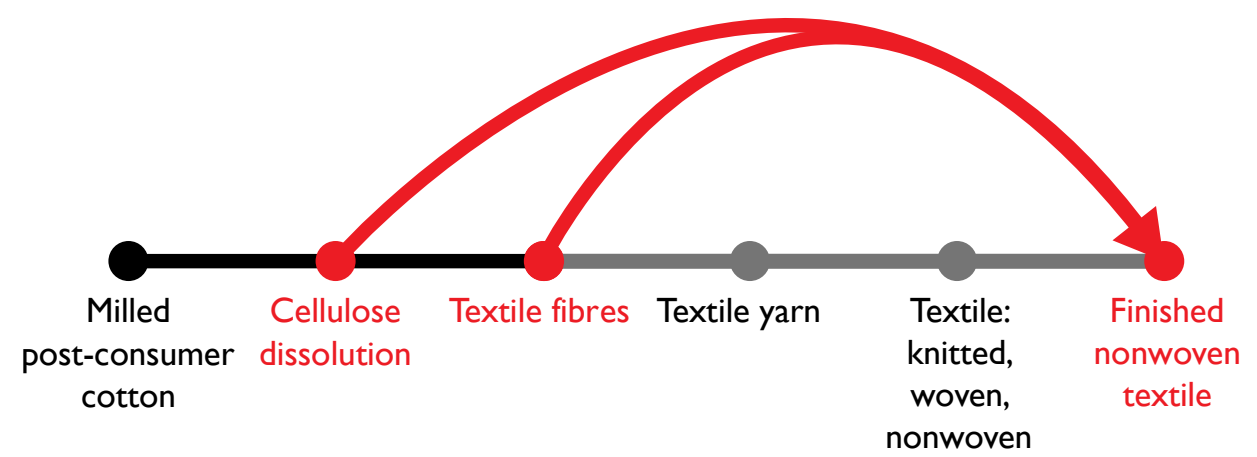

Figure 9. Diagram showing the technique using the cellulose dissolution and textile fibres for the fabrication of a finished nonwoven textile [21].

The relevance of this technique lies in the fact that any type of fibre regenerated from cellulose waste can be transformed into a textile. In other words, the technique uses low value regenerated cellulose fibres that, after chemical recycling processes in the context of a circular bioeconomy, may be spun but cannot be twisted into yarns for knitting or weaving. As a result, this technique removes the yarn processing stage in textile fabrication and is represented as the smaller Circle 2 in Figure 10. The nonwoven technique takes place after the second regeneration stage of chemically recycled, finished regenerated cellulose textiles and demonstrates an intervention in the textile value chain before a textile is produced.

The limitation of this technique is that the fibres regenerated in scientific research and commercial development are, currently, produced for high value recycled yarns [5,34,49]. Until the processes for cellulose regeneration from post-consumer textiles use regenerated fibre waste as a feedstock, this technique cannot use one hundred per cent post-consumer waste. To address this current limitation, the next section describes a fourth textile technique developed through the author's research, one that fabricates a textile solely from cellulose-based waste materials at the point of recycling and before being regenerated into a fibre form.

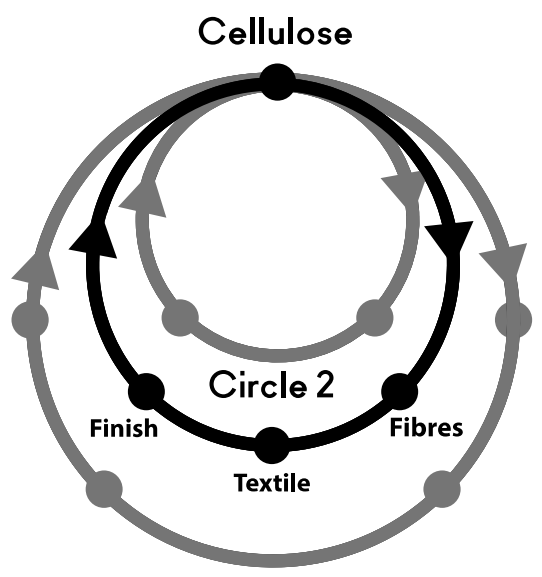

Figure 10. Nonwoven technique in Circle 2 is the second regeneration stage after circular recycling of finished regenerated cellulose textiles [21].

\subsubsection{At the Raw Material Stage}

Both the finishing and nonwoven fabrication techniques discussed in Sections 3.2.1 and 3.2.2 have the potential to create mono-material textiles for the circular bioeconomy that are made from one hundred per cent waste sources. However, both processes require a fabric or fibre substrate, which, currently, can be made partially or fully of virgin wood pulp. The practice work carried out by the author established a fourth technique that uses solely waste materials available at the chemical recycling stage [36]. Figure 11 shows how this fourth technique establishes a textile design intervention at the earliest stage 
of the textile value chain. The textile design intervention at the raw material stage is a new technique for composite fabrication using solely mechanically milled and chemically dissolved post-consumer cotton (Figure 12). A modified printing technique bonds the milled post-consumer cotton to the cellulose dissolution [48]. Iterative prototyping using different printing and drying methods achieves a mono-material textile composite with several haptic and visual textile properties such as drape, handle, lightness and breathability [48].

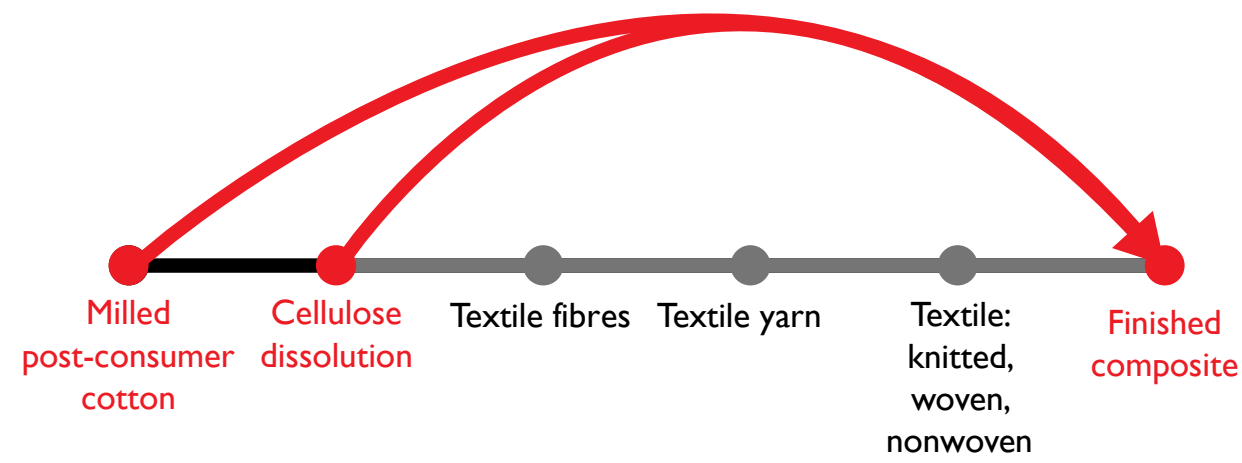

Figure 11. Diagram showing the technique using cellulose dissolution and milled post-consumer cotton for the fabrication of finished textile composites [21].

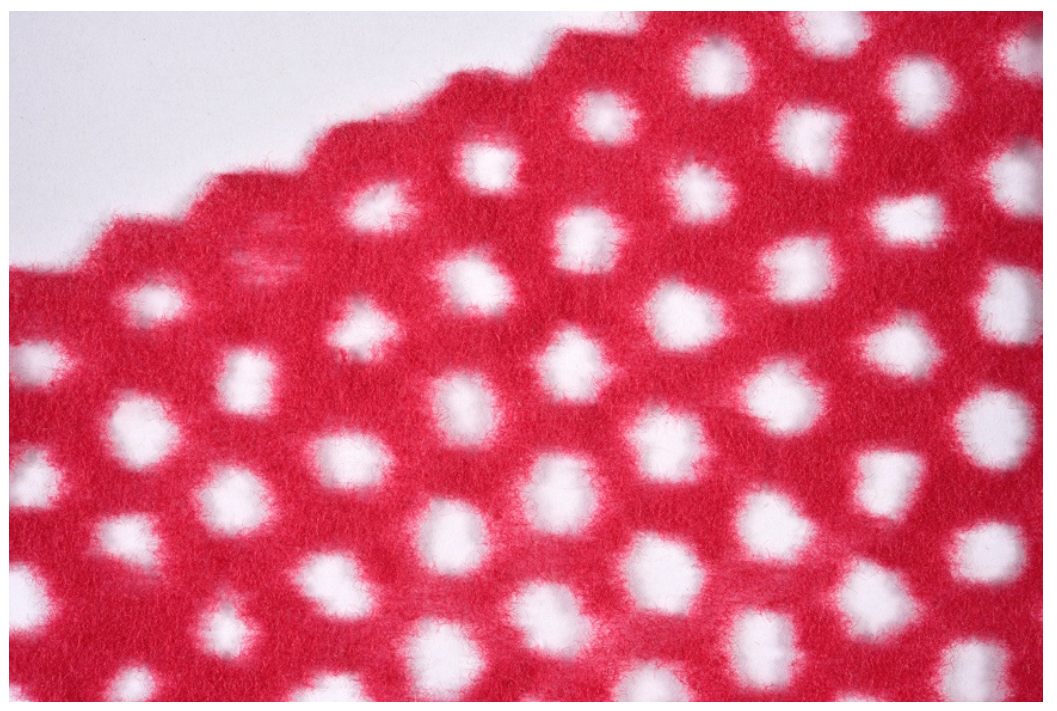

Figure 12. Textile composite fabrication at the raw material stage.

The technique here establishes a new potential for regenerated cellulose textile fabrication that is not limited by technical requirements such as spinning or by high value recycled materials such as the feedstock. In addition to this, the textile can be fabricated solely with the resources available at the recycling stage. This creates a fully integrated textile fabrication and finishing process, which can be based in recycling stages and regenerate textiles in a new value chain. The technique demonstrates the potential for the earliest possible textile design intervention for textile fabrication at the raw material stage in the circular bioeconomy between the end of life recycling and the beginning of a new lifecycle. Figure 13 shows how the technique creates the smallest loop for textile fabrication, which is independent from the stages of fibre, yarn and woven or knitted textile construction. 


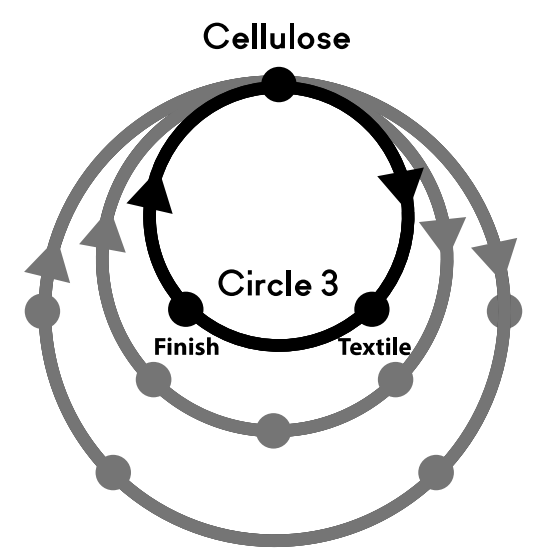

Figure 13. Textile composite fabrication in Circle 3 is the third cellulose regeneration stage after circular recycling of regenerated cellulose nonwoven textiles [21].

\section{Conclusions}

This paper discusses textile design and materials science collaborations using regenerated cellulose obtained from waste feedstock, according to their intervention in the textile value chain. In addition, it discusses four textile techniques developed from interventions at the raw state of the cellulose dissolution for recycled regenerated textile materials in the circular bioeconomy. The cellulose-based finishing, nonwoven and composite techniques stem from using a cellulose dissolution in circular recycling. Therefore, the mono-material fabrication and finishing techniques begin at the raw material stage in the textile value chain and can be introduced into a new lifecycle within the context of a circular bioeconomy. The techniques can use any type of cellulose dissolution obtained from waste textiles and respond to the changing properties of cellulose after each chemical recycling stage. For example, fibres that are not suitable for yarn spinning can be formed into a nonwoven. After the nonwoven is recycled, a textile composite can be produced. This establishes a framework for consecutive cellulose regeneration stages corresponding to four processes in circular recycling, where each cycle removes one stage in the fabrication process of textiles, catering to the properties of low value regenerated cellulose materials. Each intervention in the textile value chain can also be achieved by using high value materials such as a cellulose dissolution with a degree of polymerisation suitable for fibre spinning and woven textile construction (see Section 3.1.3) or explored using other materials with comparable properties (such as bioplastics). However, the current production model of the established textile value chain requires high value materials to be introduced as a replacement to cotton and therefore, new value chains are not considered. This paper proposes to adapt textile processes according to the properties of each material in the context of the circular bioeconomy, so that high value uses of these recycled materials can be achieved. Alternatively, the framework may be used for high value textiles when each circle represents a new use of these materials through strategies such as maintenance, remanufacture or repair, before these are regenerated for a new lifecycle: such a framework could inform further research. High and low value material applications could also be combined, such as through the upgrade or repair of a textile product using the finishing process described in Section 3.2.1. Each of the techniques in this framework result from earlier interventions in established textile processes for regenerated cellulose obtained from waste textiles: these demonstrate new resultant value chains from which new applications could emerge. Future work could further explore the products and applications resulting from these textile processes that cater to the specific properties of regenerative textiles. For example, the textile composite can be formed into different net, honeycomb or textile lace shapes depending on the pattern design introduced, which would make it suitable for mesh or lace-like textile use [36]. This textile composite can be manufactured using one hundred percent waste materials at the raw material stage of the textile value chain and is different to the established process of making transparent and flexible films in material science laboratories that lack textile 
properties [36]. In other words, a textile could be fabricated at the point of textile recycling by integrating design techniques and scientific methods for cellulose dissolution and regeneration. The finishing techniques can provide a wide range of textile applications due to a range of haptic and visual possibilities that can be achieved [48], while also offering mono-materiality that enables circular recycling processes of finished textiles to create new value chains. The cellulose-based nonwoven offers new opportunities for textile fabrication using textile design that supports the production of customised, zero waste textiles where the fibres and dissolution are adapted to a specific product shape (such as a garment). Concurrently, the nonwoven can also be fabricated at the textile recycling stage from within a materials science laboratory. Overall, all four processes offer opportunities beyond the replacement of fibres or materials in existing textile value chains. Instead, they propose new methods for customised, application-specific textile production that can take place where waste materials arise. They can also make possible variations in size, colour, texture and form in a range of haptic and visual textile properties adapted to user needs [48]. As a further step, the processes developed through design practice could be translated into digitally enabled processes using automated technologies [21]. The framework proposes a long-term view of future materials circularity of regenerated cellulose-based fibres in a circular bioeconomy beyond the replacement of fibres and materials in existing textile production processes. Furthermore, the techniques suggest opportunities for fully integrated textile fabrication and finishing processes using solely waste materials, responding to the properties of these materials through processes of cellulose-based textile recycling. The resulting textiles are compatible with the biological and technical cycles of the circular economy. In the developing of material design processes as close as possible to the raw material stage in the textile value chain of regenerated materials, the potential for future circularity becomes embedded in the results. Mapping these circular design processes according to stages in the value chain demonstrates new types of design interventions for regenerative textiles.

Funding: The PhD research was funded by the AHRC London Doctoral Design Centre (LDoc) at the University of the Arts London (UAL).

Institutional Review Board Statement: Not applicable.

Informed Consent Statement: Not applicable.

Data Availability Statement: The data presented in this study are available on request from the corresponding author. The data are not publicly available due to the embargo on the Ph.D. Thesis of the author at the time of publication of this article.

Acknowledgments: With thanks to the Centre for Circular Design at Chelsea College of Arts (UAL), where this PhD research was based, and to Kate Goldsworthy and Carole Collet for supervising the research. Thanks also to Hanna de la Motte and RISE Research Institutes of Sweden as well as to Aalto University for hosting practice elements of the research through research residencies.

Conflicts of Interest: The author declares no conflict of interest.

\section{References}

1. Kääriäinen, P.; Tervinen, L. (Eds.) Lost in the Wood(s): The New Biomateriality in Finland, 1st ed.; Aalto University: Helsinki, Finland, 2017.

2. Woodings, C. (Ed.) Regenerated Cellulose Fibres, 1st ed.; Woodhead Publishing in association with the Textile Institute: Cambridge, UK, 2000.

3. Aalto University; VTT; Tampere University of Technology. Design Driven Value Chains in the World of Cellulose DWoC 2013-2015. Available online: http:/ / www.vtt.fi/Documents/DWoC1.pdf (accessed on 28 February 2017).

4. Ma, Y.; Hummel, M.; Määttänen, M.; Sixta, H. Upcycling of Waste Paper and Cardboard to Textiles. Green Chem. 2015, 18, 858-866. [CrossRef]

5. Ma, Y.; Asaadi, S.; Johansson, L.; Ahvenainen, P.; Reza, M.; Alekhina, M.; Rautkari, L.; Michud, A.; Hauru, L.; Hummel, M.; et al. High-Strength Composite Fibers from Cellulose-Lignin Blends Regenerated from Ionic Liquid Solution. ChemSusChem 2015, 8 , 4030-4039. [CrossRef] [PubMed] 
6. Boston Consulting Group. Global Fashion Agenda. The Pulse of the Fashion Industry. Available online: https: //www.copenhagenfashionsummit.com/wp-content/uploads/2017/05/Pulse-of-the-Fashion-Industry_2017.pdf (accessed on 19 May 2017).

7. The Fiber Year. The Fiber Year 2016: World Survey on Textiles and Nonwovens; The Fiber Year GmBH: Speicher, Switzerland, 2016.

8. Östlund, Å.; Wedin, H.; Bolin, L.; Berlin, J.; Jönsson, C.; Posner, S.; Smuk, L.; Eriksson, M.; Sandin, G. Textilåtervinning: Tekniska Möjliheter och Utmaningar. Available online: https: / www.naturvardsverket.se/Documents / publikationer6400/978-91-620-668 5-7.pdf?pid=15536 (accessed on 5 July 2016).

9. Re:newcell AB. Renewcell. Available online: http:/ / renewcell.se/ (accessed on 7 November 2017).

10. MISTRA Future Fashion. Future Fashion Manifesto. Available online: http://mistrafuturefashion.com/wp-content/uploads/20 17/12/Future-Fashion-Manifesto-2015-1.pdf (accessed on 15 December 2015).

11. Gullingsrud, A.; Williams, A. Fashion Fibers: Designing for Sustainability, 1st ed.; Bloomsbury Academic: New York, NY, USA, 2017.

12. Sinclair, R. (Ed.) Textiles and Fashion: Materials, Design and Technology, 1st ed.; Woodhead Publishing in association with The Textile Institute: Cambridge, UK, 2014.

13. Lenzing. The Global Fiber Market in 2015. Available online: http://www.lenzing.com/en/investors/equity-story/global-fibermarket.html (accessed on 13 January 2017).

14. loncell. Research. Available online: https:/ /ioncell.fi/research/ (accessed on 12 February 2018).

15. Evrnu. The Problem: Textile Waste. Available online: https://www.evrnu.com/ (accessed on 26 July 2017).

16. SaXcell. Saxcell: A Revolutionary New Fibre. Available online: http:/ / saxcell.nl/ (accessed on 29 January 2019).

17. Tencel. REFIBRA: Contributing to the Circular Economy. Available online: https://www.tencel.com/refibra (accessed on 20 June 2016).

18. Worn Again Technologies. Worn Again. Available online: http://wornagain.info/ (accessed on 16 October 2017).

19. Michud, A.; King, A.W.T.; Parviainen, A.P.; Sixta, H.; Hauru, L.; Hummel, M.; Kipeläinen, I.A. Process for the Production of Shaped Cellulose Articles from a Solution Containing Pulp Dissolved in Disttilable Ionic. Liquids. Patent No. 2014/162062 A1, 4 April 2014.

20. Circulose. Project 001: The Process. Available online: https:/ / circulo.se/project_1-1 (accessed on 27 August 2021).

21. Ribul, M. Material Driven Textile Design: Designing Fully Integrated Fabrication and Finishing Processes with Regenerated Cellulose in the Materials Science Laboratory. Ph.D. Thesis, University of the Arts London, London, UK, 2019.

22. Elasser, V.H. Textiles: Concepts and Principles, 2nd ed.; Fairchild Publications Inc.: New York, NY, USA, 2005.

23. Kataja, K.; Kääriäinen, P. (Eds.) Designing Cellulose for the Future. Available online: https://cellulosefromfinland.fi/wpcontent/uploads/2018/09/DWoC_Loppuraportti_FINAL_s\%C3\%A4hk\%C3\%B6inen.pdf (accessed on 21 November 2018).

24. RISE Research Institutes of Sweden. Third Milestone Report. Available online: https://static1.squarespace.com/static/ 5891ce37d2b857f0c58457c1/t/5c0554e61ae6cfe5a110c824/1543853290648/D9.4+Third+Milestone+Report.pdf (accessed on 7 December 2018).

25. Lu, J.; Hamouda, H. Current status of Fiber Waste Recycling and Its Future. Adv. Mater. Res. 2014, 878, 122-131. [CrossRef]

26. Design Meets Cellulose. CHEMARTS. 2020. Available online: http://chemarts.aalto.fi/wp-content/uploads/2017/08/ CHEMARTS12_Collaboration.pdf (accessed on 5 October 2017).

27. American Chemical Society. Upcycling 'Fast Fashion' to Reduce Waste and Pollution. Available online: https://www.youtube. com/watch?v=BpUUWMd-05I (accessed on 18 October 2017).

28. Innventia Global Outlook. A Cellulose-Based Society, 1st ed.; Innventia AB: Stockholm, Sweden, 2016.

29. Wedin, H.; Gupta, C.; Mzikian, P.; Englund, F.; Hornbuckle, R.; Troppenz, V.; Kobal, L.; Krečič, M.; Micol Costi, M.; Ellams, D.; et al. Can automated NIR Technology Be a Way to Improve the Sorting Quality of Textile Waste? D4.1. Available online: https: / /issuu.com/trash2cash/docs/report4/1?ff=true\&e=30581983/55544808 (accessed on 27 November 2017).

30. Palme, A. Recycling of Cotton Textiles: Characterization, Pretreatment, and Purification. Ph.D. Thesis, Chalmers University of Technology, Gothenburg, Sweden, 2017.

31. Englund, F.; Wedin, H.; Ribul, M.; de la Motte, H.; Östlund, Å. Textile Tagging to Enable Automated Sorting and beyond: MISTRA Future Fashion Report. Available online: http:/ / mistrafuturefashion.com/wp-content/uploads/2018/03/AutoSort-report-D4.3 .4_3.pdf (accessed on 30 March 2018).

32. Roos, S. Advancing Life Cycle Assessment of Textile Products to Include Textile Chemicals: Inventory Data and Toxicity Impact Assessment. Ph.D. Thesis, Chalmers University of Technology, Gothenburg, Sweden, 2016.

33. Ellen MacArthur Foundation. A New Textiles Economy: Redesigning Fashion's Future. Available online: https://www. ellenmacarthurfoundation.org/assests /downloads/A-New-Textiles-Economy_Full-Report_Updated_1-12-17.pdf (accessed on 28 November 2017).

34. Hummel, M.; Michud, A.; Tanttu, M.; Netti, E.; Asaadi, S.; Ma, Y.; Sixta, H. High Strength Fibers from Various Ligno-Cellulosic Materials Using the Ioncell-F Technology. Available online: http:/ / costfp1205.com/wp-content/uploads /2017/schools/Documents / 3rdtrainingschool/2_Hummel_HighStrength.pdf (accessed on 20 June 2016).

35. The Fiber Year. The Fabric Year 2017: World Survey on Textiles and Nonwovens; The Fiber Year GmBH: Speicher, Switzerland, 2017.

36. Ribul, M.; Goldsworthy, K.; Collet, C. Material-Driven Textile Design (MDTD): A Methodology for Designing Circular MaterialDriven Fabrication and Finishing Processes in the Materials Science Laboratory. Sustainability 2021, 13, 1268. [CrossRef] 
37. Tanttu, M. Trends in Concept Design of Textile Materials. Master's Thesis, Aalto University School of Arts, Design and Architecture, Helsinki, Finland, 2015.

38. CelluloseFromFinland.fi. Functional Cellulosic Structures on Fabrics by 3D Printing. Available online: http:/ / cellulosefromfinland. fi/functional-cellulosic-structures-by-3d-printing/ (accessed on 18 May 2018).

39. Aalto University. Materials Platform. Available online: https://www.aalto.fi/aalto.fi/aalto-university-materials-platform (accessed on 10 September 2017).

40. CelluloseFromFinland.fi. Fabrics from Waste Cellulose-How to Wear Old Newspapers. Available online: http:// cellulosefromfinland.fi/ fabrics-from-waste-cellulose-how-to-wear-old-newspapers/ (accessed on 12 February 2018).

41. Saxion. People behind SaXcell. Available online: https://www.saxion.nl/site.nl/site/index/saxcell/peoplebehindSaXcell (accessed on 1 August 2016).

42. Fast Company. Peters, A. Levi's Made the First Ever 100\% Recycled Cotton Jeans (Updated). Available online: https://www. fastcompany.com/3059826/levis-made-the-first-ever-100-recycled-cotton-jeans (accessed on 26 July 2016).

43. De la Motte, H. Derivatization and Characterization of Cellulosic Materials: Synthetic Procedures towards Sustainable Reactions. Ph.D Thesis, Chalmers University of Technology, Gothenburg, Sweden, 2012.

44. CelluloseFromFinland.fi. Foam Formed Non-Wovens from Yarns and Fibres. Available online: http:/ / cellulosefromfinland.fi/ foam-formed-multi-layer-textile-structures / (accessed on 11 July 2018).

45. Ribul, M.; de la Motte, H. The Material Affinity of Design and Science for a Circular Economy. In Proceedings of the Circular Transitions Conference, London, UK, 23-24 November 2016; pp. 236-248. Available online: http:/ / circulartransitions.org/media/ downloads / Circular-Transitions-Proceedings.pdf (accessed on 15 January 2018).

46. CelluloseFromFinland.fi. 3D-Printing of Cellulose Based Materials by Nscrypt Method. Available online: https:// cellulosefromfinland.fi/3d-printing-of-cellulose-based-materials-by-nscrypt-method/ (accessed on 10 October 2018).

47. Chalmers. Cellulose from Wood Can Be Printed in 3D. Available online: https://www.chalmers.se/en/departments/chem/ news / Pages /Cellulose-from-wood-can-be-printed-in-3D.aspx (accessed on 1 March 2016).

48. Ribul, M. Novel Circular Fabrication and Finishing Processes with Regenerated Cellulose Obtained from Waste Textiles; Manuscript in preparation, Materials Science Research Centre, Royal College of Art: London, UK, 2022.

49. Spathas, T. The Environmental Performance of High Value Recycling for the Fashion Industry: LCA for Four Case Studies. Master's Thesis, Chalmers University of Technology, Gothenburg, Sweden, 2017. 